\title{
Ameliorating effect of Brassica oleracea (broccoli) extract on the myocardial damage induced by polycystic ovary syndrome in the adult female albino rat
}

\author{
Abeer El-Said El-Mehi and Manar Ali Faried*
}

*Correspondence: manarfaried@med.menofia.edu.eg

\begin{abstract}
Polycystic ovary syndrome (PCOS) is one of the most common and complex hormonal disorders affecting the females in the childbearing period. It is associated with several comorbidities recognized as cardiovascular risk factors. This study investigated, for the first time to our knowledge, the myocardial structural changes in experimental PCOS rat model and the ameliorating effects of Brassica oleracea(broccoli) extract. Forty adult female rats were divided into four groups; control, broccoli extract treated, PCOS and PCOS treated with broccoli extract. PCOS was induced by a single intramuscular injection of estradiol valerate $(\mathrm{EV})(16 \mathrm{mg} / \mathrm{kg})$. Four weeks after EV injection, broccoli extract (1 g/ $\mathrm{kg}$ dissolved in distilled water) was given orally once daily for 4 weeks. At the end of the experimental period, blood samples were collected. The myocardial specimens were processed for biochemical, histological and immunohistochemical studies. PCOS group showed oxidative stress and dyslipidemia. The myocardium exhibited many degenerative changes with significant increase in the cross-sectional area of cardiac myofibers and collagen deposition.Significant upregulation of androgen receptor, caspase-3, and glucose transporter 1 (GLUT1) with downregulation of desmin and heat shock protein 70 (Hsp70) immunoreaction was also noted. Broccoli extract exerted cardioprotective effects in PCOS through antioxidant and antiandrogen activities. The results of this work may throw more light on the myocardial damage associated with PCOS and provide a new insight into the possible use of broccoli extract to alleviate these effects.
\end{abstract}

Keywords: Myocardium, PCOS, Broccoli, Histopathology, Immunohistochemistry, Biochemistry

\section{Introduction}

Polycystic ovary syndrome (PCOS) is the most widely recognized endocrinopathy affecting females of reproductive age with a prevalence rate of 6-10\% [1]. It is no longer considered as a straightforward disorder constituting predominantly the domain of gynecologists, it is currently perceived as a metabolic issue that put the affected women at a higher risk of developing type 2 diabetes and heart diseases than the general population. Women with PCOS are exposed to cardiovascular risk factors and the syndrome may elucidate a significant proportion of heart disease diagnosed in women $[2,3]$.

The etiology of PCOS is uncertain, but hyperinsulinemia and hyperandrogenemia constitute the two principal features of this disease [4]. These characteristics can have significant associations with oxidative stress and greater cardiovascular risk [5]. Abnormal production of free radicals increases the stress on the cellular level with induction of changes in the molecular pathways that in turn underpins the pathogenesis of several diseases including cardiovascular disease (CVD) [6-8].

Glucose is a considerable source of metabolic energy for mammalian cells and can control gene transcription, enzyme activity, and hormone secretion [9]. Heart consumes more energy than other organs [10]. The lipid bilayer of plasmalemma is impermeable for glucose. In this way, glucose transport over 
the plasma layer is mediated by means of glucose transporters (GLUTs). Insulin triggers glucose uptake by increasing the translocation of these transporters $[11,12]$.

Heat shock proteins (Hsps) include several classes of functionally related families of proteins found in all organisms under normal physiological conditions. However, many types of environmental stress factors have been shown to stimulate synthesis of such proteins and hence Hsps are also called stress proteins $[13,14]$. They were found to have important roles in protecting cells against cellular stressors including heat [15,16], hypoxia [17], bright illumination [18] and oxidative pressure [19]. Moreover, $\mathrm{Hsp} 70$ was considered to have important impact in protection against stress-induced heart cell damage such as ischemia-reperfusion injury and cardiac infarctions [20].

Broccoli, a member of the Brassicaceae family, is rich in vitamins, minerals, dietary fiber, flavonol glycosides, hydroxycinnamic acids and sulphur-containing compounds $[21,22]$. Sulforaphane (SFN), a naturally-occurring sulphur-containing compound, abundant in broccoli and cabbage, has antioxidant and anti-inflammatory properties. So, it has beneficial effects in CVD [23]. In addition to the antioxidant, anticancer and anti-inflammatory activities of broccoli, it was postulated that it has an antiandrogen activity [24].

Currently, plant extracts are being widely used in the treatment of some female reproductive disorders $[25,26]$. A recent study by Nofal et al. [27] has concluded that broccoli extract presented beneficial effects on hormonal indices in a rat model of PCOS. Also, it exerted strong antioxidant potentials, promoted healthy follicles and regained the pleura of follicles. So, we were encouraged to study its possible cardioprotective effects in PCOS.

Taken together, this work was designed, for the first time to the best of our knowledge, to investigate the reflection of the main etiological factors of PCOS on the histological structure of the myocardium and whether broccoli extract can exert cardioprotective effects.

\section{Materials and Methods \\ Chemicals}

Estradiol valerate (EV), a product of (Bayer Weimar GmbHb und Co. KG Weimar- Germany a subsidiary of: Baer pharma AG, Germany), was obtained from El-Ezaby pharmacy-Cairo in the form of tablets, each containing $2 \mathrm{mg}$ of EV. The tablets were crushed and dissolved in distilled water to be given by intramuscular injection.

\section{Plant extract}

Broccoli was purchased from the market. The plant material was authenticated and extracted in Botany Department, National Research Center, El-Doki, Cairo, Egypt. Fresh broccoli florets were cleaned with tap water to remove the dirt adhering to them and were spread on tissue paper to absorb excess surface water. The plants were dried and powdered in a mechanical grinder. The powdered material was extracted successively in $80 \%$ ethanol using a Soxhlet apparatus at $45^{\circ} \mathrm{C}$ for $24 \mathrm{~h}$. The extract was concentrated in vacuo and kept in a vacuum desiccator for complete removal of solvent [28].

\section{Animals}

Forty healthy adult female albino rats at an average weight 180$200 \mathrm{~g}$ were obtained and housed at Theodor Bilharz Research Institute Animal House, Cairo, Egypt. The rats were kept in metallic cages at room temperature to keep them at healthy conditions at light/dark cycle for $12 \mathrm{~h}$ with free access to a standard palletized diet and water. The experiment was carried out in accordance with the National Institutes of Health guide for the care and use of Laboratory animals (NIH Publications No. 8023, revised 1978). All procedures were conducted in accordance with the guidelines approved by the Committee of Animal Research Ethics, Faculty of Medicine, Menoufia University.

\section{Induction of PCOS}

Polycystic ovary syndrome (PCOS) was induced by a single intramuscular injection of estradiol valerate (EV) $(16 \mathrm{mg} / \mathrm{kg}$ ) [29] dissolved in $0.2 \mathrm{ml}$ distilled water. During the experiment, the estrous cycle phases were monitored by the analysis of relative proportion of leukocytes, epithelial and cornified cells. The rats were allowed 4 weeks to establish PCOS. Cessation of cyclicity, which was shown by the persistent cornification of vaginal smears, was used as a criterion for selection of the PCOS group [30].

\section{Experimental design}

All rats were checked daily for ovarian cycle using vaginal smear for determination of the estrous cycle phases. Vaginal contents were swapped using an ear cotton rod soaked in normal saline ( $\mathrm{NaCl} 0.9 \%)$. Vaginal swap was placed on a glass slide. Unstained material was observed under the light microscope [31]. Rats with regular cycle were chosen for the experiment.

After one week of adjustment to the new environment, the rats were divided equally into four experimental groups (10 rats each); (i) control, (ii) broccoli extract treated (1 g/kg dissolved in distilled water given once daily orally by gavage for 4 weeks), (iii) PCOS induction and (iv) PCOS treated with broccoli extract (4 weeks after EV injection, broccoli extract was given at the same dose, route of administration and duration as group ii).. At the end of the experiment, the rats were anesthetized by inhalation of pentobarbital overdose $(200 \mathrm{mg} / \mathrm{kg})$, blood samples were collected from retroorbital venous plexus. A midline thoraco-abdominal incision was performed, and the heart of each rat was dissected out and washed with physiological saline. Specimens from the left ventricular tissue near the apex were taken. Each specimen was divided into two parts: one part was fixed in $10 \%$ neutral buffered formalin for light microscopic study and the second part was immediately frozen at $-70^{\circ} \mathrm{C}$ to be used for tissue 
biochemical study.

\section{Evaluation methods}

Biochemical analysis

Serum levels of total testosterone, total cholesterol (TC), Triglycerides (TG), High density lipoprotein (HDL) and low density lipoprotein (LDL) were analyzed using commercially available kits.

Cardiac tissue was homogenized in $5-10 \mathrm{ml}$ cold buffer (i.e. $50 \mathrm{mM}$ potassium phosphate, pH 7.5. $1 \mathrm{mM}$ EDTA). Homogenate was centrifuged at $10000 \times \mathrm{g}$ for 15 minutes at $4^{\circ} \mathrm{C}$. The supernatant was used for the measurement of tissue superoxide dismutase (SOD), according to the methods of Kono [32]. Meanwhile, the concentration of malondialdehyde (MDA) was measured as an index of lipid peroxidation [33].

\section{Histological and immunohistochemical studies}

Cardiac tissue samples were processed routinely by embedding in paraffin and sectioned into $5 \mu \mathrm{m}$ thick sections to be stained with hematoxylin \& eosin for routine histological assessment and Mallory trichrome stain for detection of collagen deposition.

For immunohistochemical study, the paraffin sections on poly-L-lysin coated slides were deparaffinized and rehydrated. Endogenous peroxidase was blocked by inserting the sections in 3\% hydrogen peroxide $\left(\mathrm{H}_{2} \mathrm{O}_{2}\right)$. The microwave antigen retrieval procedure was performed. The sections were incubated with primary anti androgen (rabbit monoclonal, Abcam, 1:500), anti HSP70 antibody (mouse monoclonal, Abcam, 1:100), anti caspase-3 antibody (rabbit polyclonal, Lab Vision, USA, 1:500), anti desmin (mouse monoclonal, Thermo Fisher Scientific Industries, 1:100) and anti GLUT-1 antibody (rabbit monoclonal, Abcam, 1:250). After that, biotinylated goatpolyvalent secondary antibody was applied. The sections were then incubated in preformed streptavidin peroxidase and finally the prepared DAB substrate chromogen (3,3'-diaminobenzidine tetrahydrochloride) was applied and the slides were counterstained with hematoxylin to be examined under light microscope.

\section{Quantitative assessment}

Using Image J software, version K 1.45 , the following parameters were measured:

1. The cross-sectional area of cardiac myocytes and area \% of collagen deposition.

2. The area \% of caspase-3, HSP70, desmin and GLUT 1 immunoreaction.

3. The number of androgen receptor positive cells. For each parameter, ten non-overlapping fields $(40 \mathrm{x})$ for every specimen were examined.

\section{Statistical analysis}

The data were collected, tabulated and analyzed by SPSS (statistical package for social science) version 23.0 on IBM compatible computer (SPSS Inc., Chicago, IL, USA). The obtained data were analyzed using one way-ANOVA followed by post hoc Bonferroni test. A $p$ value of $<0.05$ was considered statistically significant and $P$ value $>0.05$ was considered non-significant.

\section{Results}

There was a non-significant difference between the control group and the broccoli extract treated group throughout all the examined parameters. So, they were pooled in a one "control" group.

\section{Biochemical results}

\section{Serum testosterone level and lipid profile}

Estradiol valerate induced PCOS caused significant increase in serum level of total testosterone, triglyceride (TG), total cholesterol $(\mathrm{CH})$, low density lipoprotein (LDL) and significant decrease in high density lipoprotein (HDL) as compared to the control group. Polycystic ovary group treated with broccoli extract exhibited a significant decrease in the serum level of total testosterone,TG, $\mathrm{CH}$ and LDL and a significant increase in the level of HDL compared to PCOS group (Table 1).

Table 1. Serum testosterone level and lipid profile of the different groups.

\begin{tabular}{llll}
\hline Serum level & Control & PCOS & $\begin{array}{l}\text { PCOS treated } \\
\text { with broccoli } \\
\text { extract }\end{array}$ \\
\hline $\begin{array}{l}\text { Total testosterone } \\
(\mathrm{ng} / \mathrm{dl})\end{array}$ & $3.61 \pm 0.48$ & $117.18 \pm 4.34 \mathrm{a}^{* * *}$ & $18.27 \pm 2.10 \mathrm{~b}^{* * *}$ \\
$\begin{array}{l}\text { Triglyceride }(\mathrm{mg} / \mathrm{dl}) \\
\text { Total cholesterol }(\mathrm{mg} / \mathrm{dl})\end{array}$ & $61.10 \pm 3.07$ & $137.10 \pm 4.48 \mathrm{a}^{* * *}$ & $70.00 \pm 3.39 \mathrm{~b}^{* * *}$ \\
$\begin{array}{l}\text { Low density lipoprotein } \\
(\mathrm{mg} / \mathrm{dl})\end{array}$ & $33.90 \pm 3.84$ & $59.00 \pm 4.47 \mathrm{a}^{* * *}$ & $40.80 \pm 2.48 \mathrm{~b}^{* * *}$ \\
High density lipoprotein & $40.50 \pm 3.97$ & $16.70 \pm 2.05 \mathrm{a}^{* * *}$ & $31.90 \pm 2.68 \mathrm{~b}^{* * *}$
\end{tabular}

$(\mathrm{mg} / \mathrm{dl})$

$\mathrm{a}^{* * *} \mathrm{P}<0.001 \mathrm{PCOS}$ vs control.

$\mathrm{b}^{\star * *} \mathrm{P}<0.001$ PCOS treated with broccoli extract vs PCOS.

Tissue malondialdehyde and superoxide dismutase levels The myocardium of the PCOS group showed a significant increase in the malondialdehyde (MDA), level and a significant decrease in the level of superoxide dismutase (SOD) compared to that of the control group. On contrary, the PCOS group treated with broccoli extract revealed a marvelous beneficial effect via a significant decrease in the MDA and a significant increase in the SOD level within the myocardium when compared to that of the PCOS untreated group (Table 2).

\section{Histological results \\ Hematoxylin and eosin (H\&E)}

Hematoxylin and eosin (H\&E) stained sections of the different experimental groups were examined under light microscope. The control group showed organized branching and anas- 
Faried et al., Journal of Histology \& Histopathology 2019,

http://www.hoajonline.com/journals/pdf/2055-091X-6-8.pdf

Table 2. Tissue level of MDA and SOD in the different groups.

\begin{tabular}{llll}
\hline Tissue Level & Control & PCOS & $\begin{array}{l}\text { PCOS treated } \\
\text { with broccoli } \\
\text { extract }\end{array}$ \\
\hline MDA (nmol/mg) & $1.25 \pm 0.17$ & $5.99 \pm 0.54 \mathrm{a}^{* * *}$ & $2.72 \pm 0.31 \mathrm{~b}^{* * *}$ \\
SOD (U/mg) & $38.35 \pm 1.41$ & $9.65 \pm 0.77 \mathrm{a}^{* * *}$ & $32.16 \pm 1.28 \mathrm{~b}^{* * *}$ \\
\hline
\end{tabular}

$\mathrm{a}^{* * *} \mathrm{P}<0.001$ PCOS vs control.

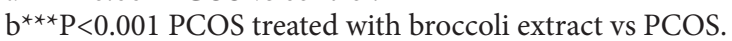

tomosing cardiac muscle fibers with acidophilic sarcoplasm, single, oval and centrally located nuclei of cardiomyocytes, and intact intercalated discs. Moreover, flat dark nuclei of the fibroblasts were observed in the interstitial tissue (Figure 1a). On the other hand, PCOS group displayed disruption of the cardiac structure in the form of fragmented degenerated fibers with rarified vacuolated sarcoplasm. In addition, widely separated myofibers with homogenous highly acidophilic sarcoplasm (hyalinized), myocytolysis, congested dilated blood vessels, extravasation, pyknotic nuclei and inflammatory infiltrate were noted (Figures $\mathbf{1 b} \mathbf{b} \mathbf{1} \mathbf{e}$ ). These changes were ameliorated in the PCOS group treated with broccoli extract except for slight separation of some muscle fibers (Figure 1f).

\section{Statistical results of cross-sectional area}

Statistically, there was a significant increase $(P<0.001)$ in the cross-sectional area $(\mu \mathrm{m} 2)$ of the cardiomyocyte of the PCOS group compared to that of the control group $(271.41 \pm 11.56$ vs $31.38 \pm 2.07)$. The PCOS group treated with broccoli extract revealed a dramatic decrease $(P<0.001)$ in the cross-sectional area $(\mu \mathrm{m} 2)$ of the cardiomyocyte compared to that of the PCOS group (41.95 \pm 1.80 vs $271.41 \pm 11.56$ ) (Figure 2$)$.

\section{Mallory trichrome (area\%of collagen deposition)}

Mallory trichrome stained sections of the different experimental groups revealed a significant increase $(P<0.001)$ in the area $\%$ of collagen deposition within the myocardium of the PCOS group stained sections compared to the control group $(49.72 \pm 1.08$ vs $17.21 \pm 0.91)$. On the other hand, the area \% of collagen deposition was significantly decreased $(P<0.001)$ in the PCOS group treated with broccoli extract compared to that of PCOS (17.42 \pm 1.00 vs $49.72 \pm 1.08)$ (Figures 3 and 4 )

\section{Immunohistochemical results}

\section{Androgen receptor immunoreaction}

The number of positive immunoreactive androgen receptor was significantly upregulated $(P<0.001)$ in the myocardium of PCOS group compared with the control group (38.20 \pm 2.57 vs $4.00 \pm 1.15)$. In contrast, a significant downregulation $(P<0.001)$ was observed in PCOS group treated with broccoli extract compared with that of PCOS group ( $5.30 \pm 1.33$ vs $38.20 \pm 2.57$ ) (Figure 5a-5c and Figure 6).

\section{HSP70 immunoreaction}

There was a significant decrease $(P<0.001)$ in the mean area\%

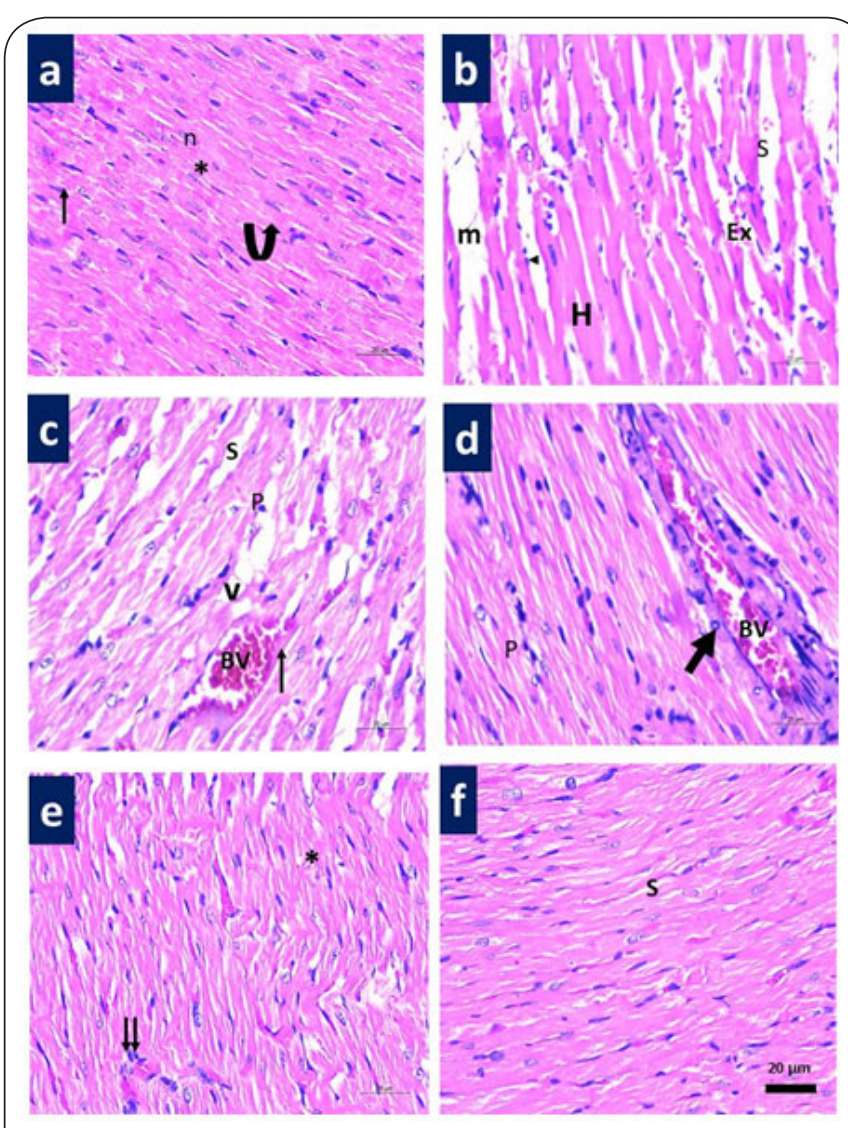

Figure 1. Representative photomicrographs of longitudinal sections of the myocardium of the different experimental groups. a: Control group showing regularly arranged branching cardiac muscle fibers (asterisk), cardiomyocytes with centrally located oval nuclei (n), intact intercalated discs (curved arrow) and fibroblasts in the interstitial tissue (arrow). (b-e): PCOS group displaying distorted cardiac architecture in the form of massive separation $(\mathrm{S})$ of hyalinized $(\mathrm{H})$ cardiac myofibers, internalization of the nuclei (arrow head) and myocytolysis (m). Some areas showing rarified vacuolated (V) sarcoplasm and pyknotic nuclei (P). Focal areas reveal disarrayed myofibers (asterisk) with inflammatory infiltration (double arrows). Extravasation (Ex), dilated congested blood vessels (BV) with thick wall (thin arrow) and perivascular inflammatory infiltrates (thick arrow) are noticed. (f): PCOS group treated with broccoli extract showing more or less restoration of the normal cardiac architecture except for slight separation (S) of the myofibers. (H\&E, Scale bar $20 \mu \mathrm{m}, 40 \mathrm{x}$ ).

of HSP70 in the PCOS group compared with the control group $(16.61 \pm 1.90$ vs $44.56 \pm 2.96)$ that was dramatically increased $(\mathrm{P}<0.001 \mathrm{P})$ in PCOS group treated with broccoli extract compared to the PCOS group ( $37.00 \pm 1.87$ vs $16.61 \pm 1.90)$ (Figure 5d-5f and Figure 6).

\section{Caspase-3 immunoreaction}

Moreover, in PCOS group, area \% of caspase-3 immunoreaction, a marker for apoptosis, was significantly upregulated $(P<0.001)$ compared with the control group(36.69 \pm 2.06 vs $5.05 \pm 0.51)$. On the other hand, a significant downregulation $(\mathrm{P}<0.001)$ in 
Faried et al., Journal of Histology \& Histopathology 2019,

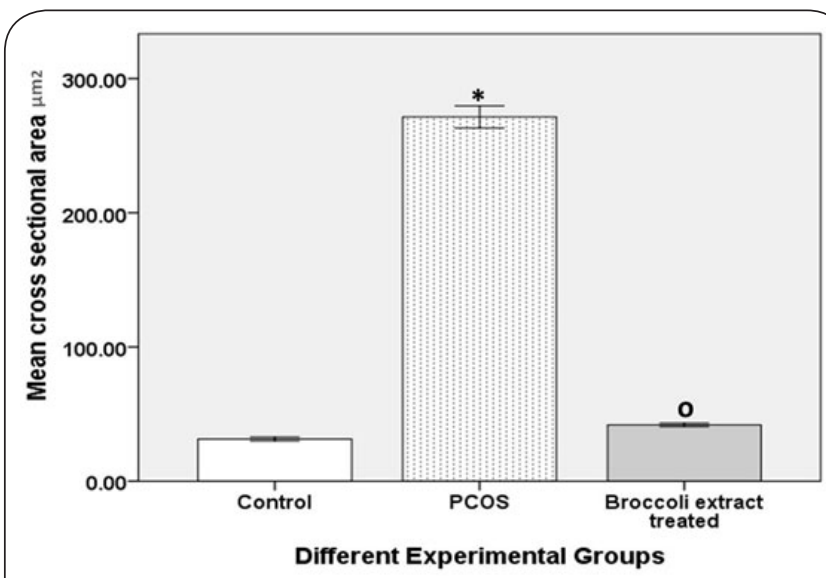

Figure 2. A histogram showing a significant increase $(\mathrm{P}<0.001)$ in the cross-sectional area of the cardiomyocytes in PCOS group $\left(^{*}\right)$ compared to the control group and a significant decrease $(\mathrm{P}<0.001)$ in the PCOS group treated with broccoli extract (o) compared to the PCOS group.

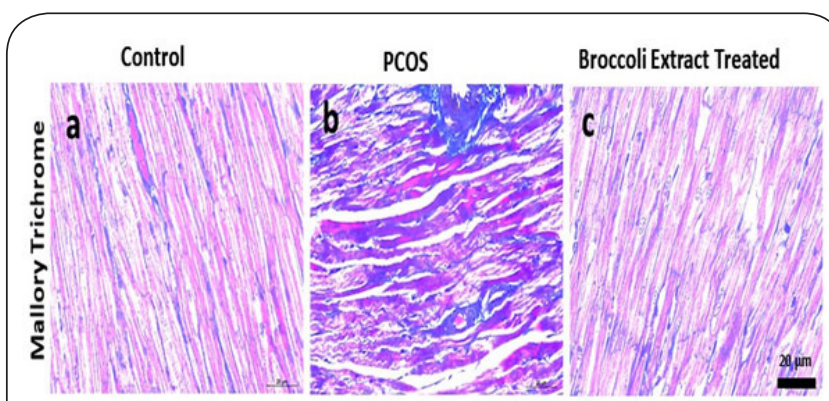

Figure 3. Representative photomicrographs of the different experimental groups showing increased collagen deposition in the myocardium of the PCOS group (b) compared to that of the control (a) and PCOS group treated with broccoli extract (c) (Mallory Trichrome, Scale bar $20 \mu \mathrm{m}, 40 \mathrm{x}$ ).

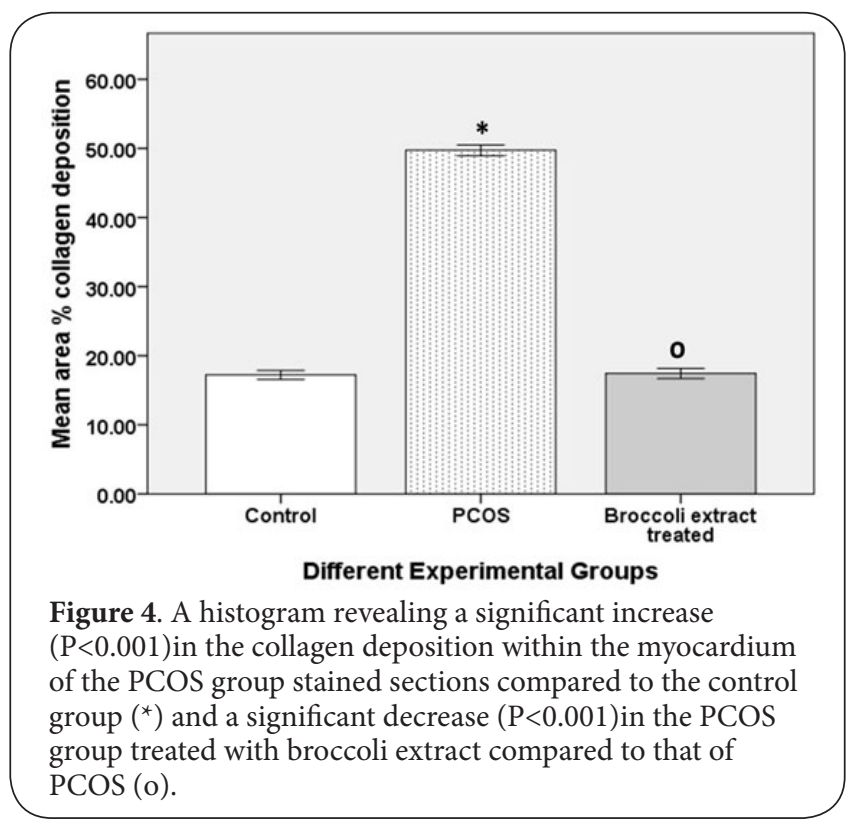

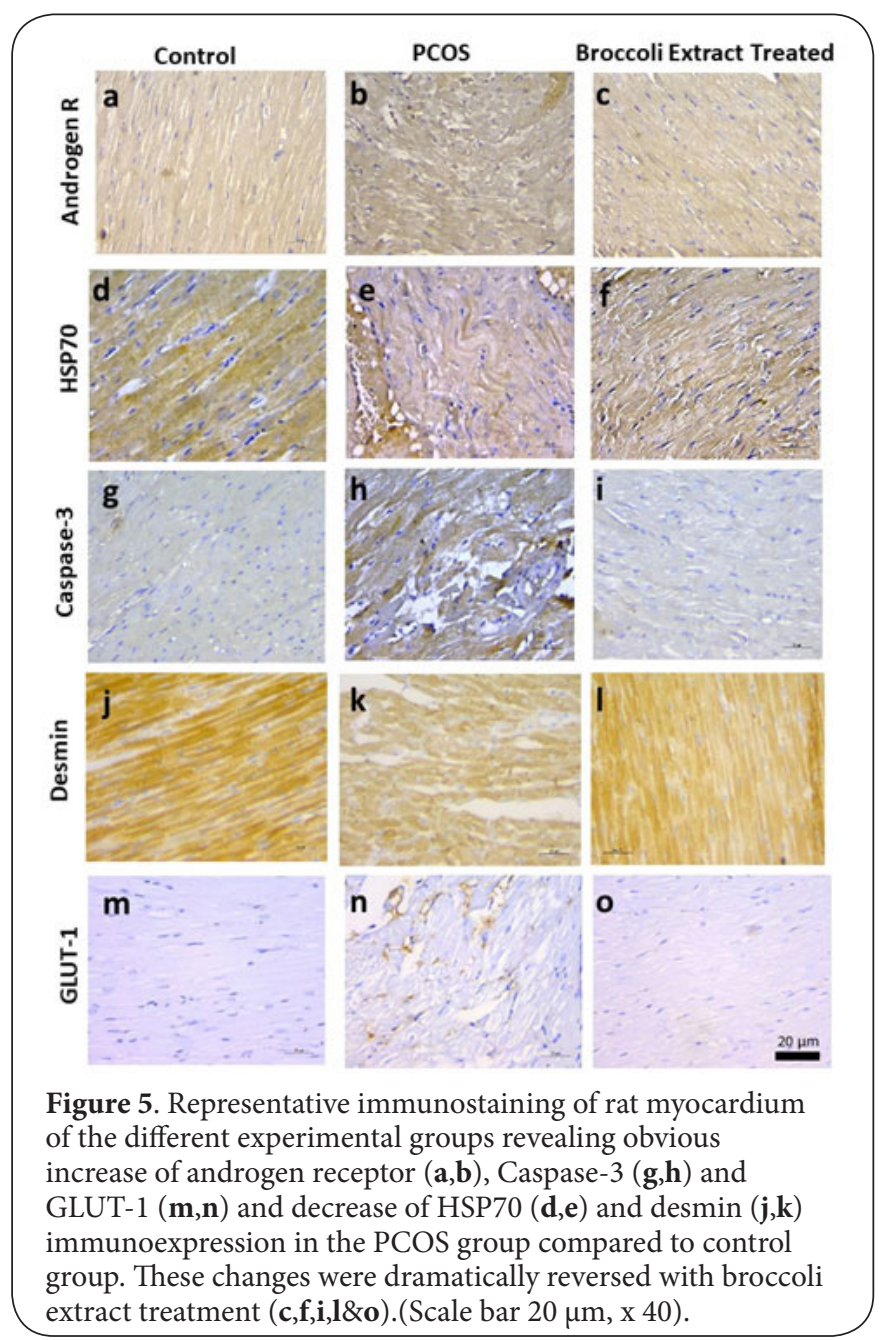

PCOS group treated with broccoli extract compared to the PCOS group (7.86 \pm 0.51 vs $36.69 \pm 2.06$ ) was observed (Figure 5g-5i and Figure 6).

\section{Desmin immunoreaction}

Desmin area \% immunoexpression was significantly decreased $(\mathrm{P}<0.001)$ in the $\mathrm{PCOS}$ rats compared with the control group $(16.13 \pm 1.01$ vs $52.01 \pm 2.30)$ and this was dramatically increased $(\mathrm{P}<0.001)$ in the PCOS group treated with broccoli extract compared to the PCOS group $(41.88 \pm 1.02$ vs $16.13 \pm 1.01)$ (Figure 5j-5I and Figure 6).

\section{GLUT-1 immunoreaction}

A significant upregulation $(P<0.001)$ of GLUT-1 area \% immunoreaction was noted in the myocardium of the PCOS group compared to that of the control group (14.13 \pm 1.02 vs $1.09 \pm 0.24)$. On contrast, this expression was significantly decreased $(\mathrm{P}<0.001)$ in the PCOS group treated with broccoli extract when compared to that of PCOS group ( $1.83 \pm 0.35$ vs 14.13 \pm 1.02 ) (Figure 5m-5o and Figure 6). 


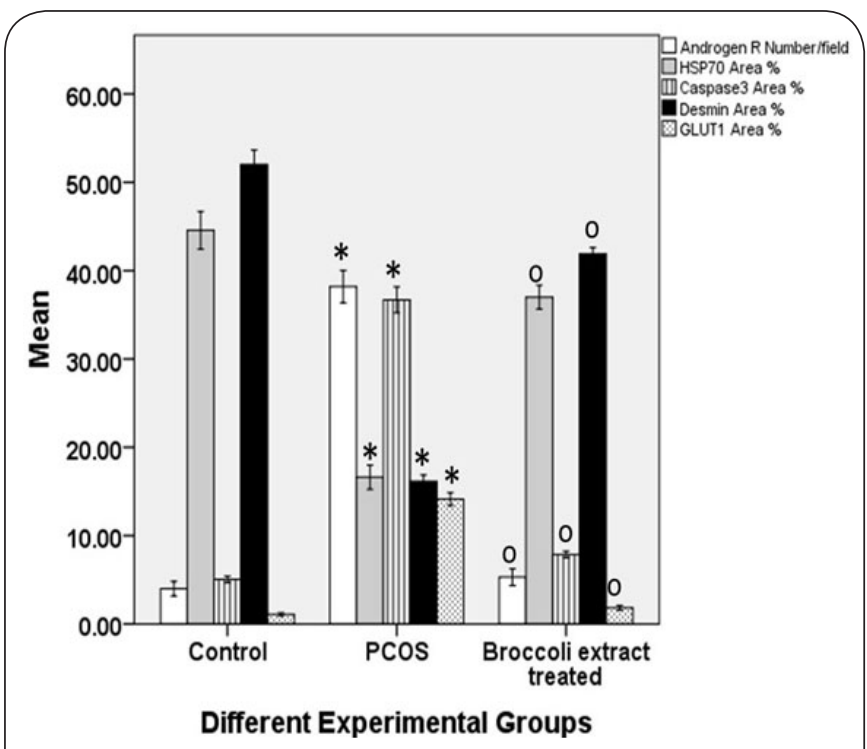

Figure 6. A histogram showing a significant increase in the number of androgen receptors and the area $\%$ of caspase- 3 and GLUT-1 $\left(^{*}\right)$ with a significant decrease in the area \% of desmin and HSP-70 $\left(^{*}\right)$ in the PCOS group as compared to the control group. The PCOS group treated with broccoli extract revealed significant amelioration of these effects compared to the PCOS group (o).

\section{Discussion}

Although cardiovascular disease (CVD) was already studied in women with PCOS or animal models of the syndrome, there's no data, up to our knowledge, regarding histopathological changes in the heart in such cases. Moreover, CVD outcomes of PCOS necessitate early intervention programs and preventative strategies to reduce mortality from cardiovascular events. Accordingly, this work was set to investigate, for the first time up to the best of our knowledge, the reflection of cardiovascular risk factors associated with PCOS on the histopathological alterations in the cardiac muscle of adult female albino rats and whether broccoli extract can ameliorate these effects.

In this work, we used a model in which PCOS was induced by a single intramuscular injection of estradiol valerate (EV) as employed by previous studies [29,34]. Estradiol valerate was reported to induce morphological changes in the ovaries like those of PCOS women. This corresponds to the persistent cornification of vaginal smears observed at the beginning of this study as well as the presence of many atretic follicles and cysts in ovarian specimens as reported previously [27].

Our results reproduced the findings of previous studies where PCOS induced group showed significant increase in serum level of triglyceride (TG), total cholesterol (CH), low density lipoprotein (LDL) and significant decrease in high density lipoprotein (HDL) $[35,36]$. Previous studies $[37,38]$ attributed imbalances in lipid profile in PCOS to hyperandrogenemia as confirmed in our study by the significant increase in the total testosterone level. Gardner et al. [39] postulated that small, dense LDL particles have been linked with a 3- to 7-fold increased relative risk of coronary artery disease. Dahlgren et al. [40]; Holte et al. [41] documented that early and prolonged exposure to dyslipidemia, i.e. lessened HDL and more levels of plasma triglycerides, LDL and total cholesterol [42], confer significant cardiovascular risk. Desai et al. [26]; Sasikala and Shamila [43] confirmed that dyslipidemia is a root cause of CVD in PCOS patients.

In the present work, PCOS animals exhibited significant oxidative stress in the form of depletion of the endogenous antioxidant SOD and increase of lipid peroxidation (MDA) in myocardial tissue. This was previously proposed by many researches and was implicated in the pathogenesis of the disease as well as its sequelae including CVD [44-46]. Elahi et al. [47] concluded that cardiovascular disease mechanisms are strongly linked to the production of reactive oxidant species and the dysregulation of oxidant-antioxidants pathways. They explained that the oxidation and nitration of cellular proteins, lipids and nucleic acids, and formation of aggregates of oxidized molecules underlie the loss of cellular function, cellular aging and the inability of cells to withstand physiological stresses. Oxidative stress causes depolarization of the inner mitochondrial membrane with subsequent release of cytochrome $\mathrm{c}$ into the cytosol leading to induction of caspase mediated apoptosis [48]. This was reflected in myocardial sections of PCOS group, in this study, as significant upregulation of caspase-3 immunoreaction. In line with this, Kuyucu et al. [49] has reported a significant increase in caspase-3 staining in uterine specimens of PCOS female rats.

Our results showed that PCOS is associated with obvious histomorphological changes in the myocardium in the form of loss of normal architecture with degenerated hyalinized myofibers, rarified vacuolated sarcoplasm and pyknotic nuclei. Degeneration of cardiac myocytes may occur because of increased protein degradation and decreased myofibrillar protein synthesis where accumulation of reactive free radicals might facilitate the release of lysosomal enzymes into the cytosol with subsequent oxidation of the protein backbone of myofibrils causing their fragmentation [50].

In this study, Hsp70 was found to be downregulated in myocardial specimens of the PCOS group. This may be explained by the results of Chen et al. [51] who found overexpression of Hsp70 level, in myocardial cells, at the acute stage that was decreased at the later stages of stress exposure. They attributed that to the tolerance to stress following chronic exposure or due to material deficiencies following long term stress. Similarly, Khan et al. [52] reported that Hsp70 and Hsp90 in the heart of broiler chickens were significantly upregulated after the exposure to heat stress for two hours and then downregulated rapidly with further exposure. They related the upregulation of these stress proteins in heart to their role as important biomarkers and protective proteins at the start of stress and that the low signals of Hsps indicate 
that myocardial cell lesions may adversely affect the function of Hsps under stress conditions.

Hyperandrogenism was proved, in this work, by the sig nificant increase of serum testosterone as well as androgen receptor (AR) immunostaining in PCOS group. Pournaderi et al. [53] explained that insulin resistance, associated with PCOS, results in compensatory hyperinsulinemia which stimulates the androgen synthesis in ovarian theca cells that is considered as the pathogenic cause of the hyperandrogenemia in PCOS. Previous researches have demonstrated the occurrence of cardiac hypertrophy with hyperandrogenism $[\mathbf{5 4 , 5 5}]$. This was confirmed, in the current study, by the significant increase of the cross-sectional area of cardiac muscle fibers and the area percent of collagen deposition in PCOS group. Marsh et al. [56]; Basualto-Alarcón et al. [57]; Hou et al. [55] concluded that androgens can activate the intracellular AR pathway to induce hypertrophy in cardiomyocytes and skeletal muscle. Myocardial fibrosis was reported to be an important histopathological change during cardiac hypertrophy [58]. Excess deposition of fibrotic extracellular matrix by fibroblasts leads to stiffness and organ dysfunction and activated fibroblasts can directly cause hypertrophy of cardiomyocytes, damages mechano-electric coupling of cardiomyocytes and accelerates the risk of arrhythmias along with tissue hypoxia and loss of myocytes [59].

Glucose transporter 1 (GLUT1) immunoexpression was found, in this study, to be significantly upregulated in PCOS myocardial specimens. Similar results were reported by Corbould et al. [60] who found significant increase of GLUT1 expression in cultured myotubes from women with PCOS. In line with our results, Montessuit and Thorburn [61] observed increased expression of GLUT1 in hypertrophied hearts both in vitro and in vivo. This can be explained by the results of previous studies which found decreased long-chain fatty acid utilization in case of cardiac hypertrophy with a compensatory shift of metabolism towards glucose utilization [62-64]. Moreover, Stenbit et al. [65] suggested that upregulation of GLUT1 may serve as a compensatory mechanism for the decreased GLUT4 mRNA and protein observed in hypertrophied hearts of human patients and animal models. Liao et al. [66] demonstrated that increasing myocardial glucose uptake protects against the progression to heart failure and improves survival in mice with chronic pressure overload. However, initial compensatory response is followed by a process of deleterious remodeling in which the hypertrophied heart dilates and fails to contract effectively [67].

Desmin is a cytoskeleton intermediate filament protein that is exclusively expressed in muscle cells [68]. The desmin network, which connects the Z-disks in adjacent myofibrils and the myofibrils to nuclear envelope and sarcolemma, is critical for the structural integrity of cardiomyocytes [69]. Also, desmin might be involved in the regulation of gene expression, myofibrillogenesis and intercellular signaling [70] and be responsible for shape and tension of the cell membrane and other organelles [71]. Changes of the cytoskeleton expressed as decreased or increased desmin immunostaining are known features related to myocardial tissue injury. These have been shown in experimental studies [72] and human heart diseases [73-75]. In this work, we found significant downregulation of desmin expression, in PCOS specimens, as compared to controls. Similar results were reported by Pawlak et al. [76]; Pawlak et al. [77] who studied patterns of desmin distribution in cardiomyopathy. Thornell et al. [78]; Capetanaki et al. [79]; Milner et al. [80] concluded that desmin deficiency leads to cardiomyocyte hypertrophy and cardiac dilatation with compromised systolic function.

Our study revealed that broccoli extract was able to act as a cardioprotective agent in PCOS female rats. Broccoli was proved to have antioxidant and antiandrogen activities $[24,81,82]$. This was reflected as the significant improvement observed in biochemical parameters as well as histopathological changes of the myocardium in PCOS group treated with broccoli extract. The effect of dietary broccoli was previously evaluated in the prevention of ischemia-reperfusion injury to the heart by Mukherjee et al. [83]. They found decreased infarct size and decreased apoptosis of cardiomyocytes with broccoli treatment suggesting cardioprotection. Similarly, and in line with our results, stroke-prone SHRsp rats were fed a diet containing broccoli sprouts from the age of 5 weeks [84]. These rats were found to have significantly higher tissue reduced glutathione (GSH) levels (aorta, heart, kidney) and lower blood pressure than their control-fed counterparts, which spontaneously developed oxidative stress, loss of tissue GSH and elevated blood pressure. Moreover, a recent study by Shawky et al. [82] reported that sulforaphane (SFN) showed insulin-sensitizing, hepatoprotective and vasculoprotective effects in fructose-fed rats. They explained these effects based on SFN-mediated antioxidant, dyslipidemia-improving and anti-inflammatory effects. SFN mediated antioxidant effects may have occurred through activation of the transcription factor; nuclear factor-erythroid 2-related factor 2 (Nrf2), which increases gene expression of endogenous antioxidant proteins such as SOD [85,86]. Moreover, quercetin, a flavonoid present in broccoli, was proved to have the potentials to alleviate the hormonal and metabolic disturbances occurring in PCOS [87].

\section{Conclusion}

The findings of the current study can provide histopathological and immunohistochemical confirmation for the harmful effects of PCOS on the heart allowing a more comprehensive understanding of the underlying mechanisms. Moreover, broccoli extract intake was proved to offer cardioprotection through its antioxidant, antiandrogen and dyslipidemiaimproving effects.

\section{Competing interests}

The authors declare that they have no competing interests. 
Faried et al., Journal of Histology \& Histopathology 2019,

\section{Authors' contributions}

\begin{tabular}{|l|c|c|}
\hline Authors' contributions & AEE & MAF \\
\hline Research concept and design & $\checkmark$ & $\checkmark$ \\
\hline Collection and/or assembly of data & $\checkmark$ & $\checkmark$ \\
\hline Data analysis and interpretation & $\checkmark$ & $\checkmark$ \\
\hline Writing the article & $\checkmark$ & $\checkmark$ \\
\hline Critical revision of the article & $\checkmark$ & $\checkmark$ \\
\hline Final approval of article & $\checkmark$ & $\checkmark$ \\
\hline Statistical analysis & $\checkmark$ & $\checkmark$ \\
\hline
\end{tabular}

\section{Publication history}

Editor: Giuseppe Musumeci, University of Catania, Italy.

Received: 11-Aug-2019 Final Revised: 23-oct-2019

Accepted: 15-Nov-2019 Published: 24-Nov-2019

\section{References}

1. Azziz R. Polycystic ovary syndrome. Obstet Gynecol. 2018; 132:321136.

2. Moran LJ, Misso ML, Wild RA and Norman RJ. Impaired glucose tolerance, type 2 diabetes and metabolic syndrome in polycystic ovary syndrome: a systematic review and meta-analysis. Hum Reprod Update. 2010; 16:347-63. | Article | PubMed

3. Bilal M, Haseeb A and Rehman A. Relationship of Polycystic Ovarian Syndrome with Cardiovascular Risk Factors. Diabetes Metab Syndr. 2018; 12:375-380. | Article | PubMed

4. Hyderali BN and Mala K. Oxidative stress and cardiovascular complications in polycystic ovarian syndrome. Eur J Obstet Gynecol Reprod Biol. 2015; 191:15-22. | Article | PubMed

5. Legro RS. Polycystic ovary syndrome and cardiovascular disease: a premature association? Endocr Rev. 2003; 24:302-12. | Article | PubMed

6. Pacher $P$ and Szabo C. Role of the peroxynitrite-poly(ADP-ribose) polymerase pathway in human disease. Am J Pathol. 2008; 173:2-13. I Article | PubMed Abstract | PubMed FullText

7. Vassalle C, Pratali L, Boni C, Mercuri A and Ndreu R. An oxidative stress score as a combined measure of the pro-oxidant and anti-oxidant counterparts in patients with coronary artery disease. Clin Biochem. 2008; 41:1162-7. | Article | PubMed

8. Moris D, Spartalis M, Spartalis E, Karachaliou GS, Karaolanis GI, Tsourouflis G, Tsilimigras DI, Tzatzaki E and Theocharis S. The role of reactive oxygen species in the pathophysiology of cardiovascular diseases and the clinical significance of myocardial redox. Ann Transl Med. 2017; 5:326. | Article | PubMed Abstract | PubMed FullText

9. Thorens $B$ and Mueckler M. Glucose transporters in the 21st Century. Am J Physiol Endocrinol Metab. 2010; 298:E141-5. I Article I PubMed Abstract | PubMed FullText

10. Shao D and Tian R. Glucose Transporters in Cardiac Metabolism and Hypertrophy. Compr Physiol. 2015; 6:331-51. | Article I PubMed Abstract | PubMed FullText

11. Gosteli-Peter MA, Schmid C and Zapf J. Triiodothyronine increases glucose transporter isotype 4 mRNA expression, glucose transport, and glycogen synthesis in adult rat cardiomyocytes in long-term culture. Biochem Biophys Res Commun. 1996; 221:521-4. | Article | PubMed

12. Szablewski L. Glucose transporters in healthy heart and in cardiac disease. Int J Cardiol. 2017; 230:70-75. I Article I PubMed

13. Pesonen E, Paakkari I and Rapola J. Infection-associated intimal thickening in the coronary arteries of children. Atherosclerosis. 1999; 142:425-9. | Article | PubMed

14. Ghayour-Mobarhan M, Saber $\mathrm{H}$ and Ferns GA. The potential role of heat shock protein 27 in cardiovascular disease. Clin Chim Acta. 2012; 413:15-24. | Article | PubMed

15. Cvoro A, Dundjerski J, Trajkovic D and Matic G. Heat stress affects the glucocorticoid receptor interaction with heat shock protein Hsp70 in the rat liver. Biochem Mol Biol Int. 1998; 46:63-70. I Article I PubMed

16. Evdonin AL, Guzhova IV, Margulis BA and Medvedeva ND. Extracellular heat shock protein $\mathbf{7 0}$ mediates heat stress-induced epidermal growth factor receptor transactivation in A431 carcinoma cells. FEBS Lett. 2006; 580:6674-8. | Article | PubMed

17. Dwyer BE, Nishimura RN and Brown IR. Synthesis of the major inducible heat shock protein in rat hippocampus after neonatal hypoxia-ischemia. Exp Neurol. 1989; 104:28-31. | Article | PubMed

18. Li HM, Niki T, Taira T, Iguchi-Ariga SM and Ariga H. Association of DJ-1 with chaperones and enhanced association and colocalization with mitochondrial Hsp70 by oxidative stress. Free Radic Res. 2005; 39:10919. | Article | PubMed

19. Drummond IA and Steinhardt RA. The role of oxidative stress in the induction of Drosophila heat-shock proteins. Exp Cell Res. 1987; 173:439-49. | Article | PubMed

20. Lepore DA, Knight KR, Anderson RL and Morrison WA. Role of priming stresses and $\mathrm{Hsp70}$ in protection from ischemia-reperfusion injury in cardiac and skeletal muscle. Cell Stress Chaperones. 2001; 6:93-6. | Article | PubMed Abstract | PubMed FullText

21. El-Magd MMA. Evaluation of some broccoli cultivars growth, head yield and quality under different planting dates. J App/ Sci Res. 2013; 9:57305736.

22. Lee SG, Kim JH, Son MJ, Lee EJ, Park WD, Kim JB, Lee SP and Lee IS. Influence of extraction method on quality and functionality of broccoli juice. Prev Nutr Food Sci. 2013; 18:133-8. | Article | PubMed Abstract | PubMed FullText

23. Bai Y, Wang X, Zhao S, Ma C, Cui J and Zheng Y. Sulforaphane Protects against Cardiovascular Disease via Nrf2 Activation. Oxid Med Cell Longev. 2015; 2015:407580. | Article | PubMed Abstract | PubMed FullText

24. Hwang C, Sethi S, Heilbrun LK, Gupta NS, Chitale DA, Sakr WA, Menon M, Peabody JO, Smith DW, Sarkar FH and Heath El. Anti-androgenic activity of absorption-enhanced 3, 3'-diindolylmethane in prostatectomy patients. Am J Transl Res. 2016; 8:166-76. I PubMed Abstract I PubMed FullText

25. Grant P. Spearmint herbal tea has significant anti-androgen effects in polycystic ovarian syndrome. A randomized controlled trial. Phytother Res. 2010; 24:186-8. | Article | PubMed

26. Desai BN, Maharjan RH and Nampoothiri LP. Aloe barbadensis Mill. formulation restores lipid profile to normal in a letrozole-induced polycystic ovarian syndrome rat model. Pharmacognosy Res. 2012; 4:109-15. | Article | PubMed Abstract | PubMed FullText

27. Nofal EA, El-Habeby MM, El-Kholy WB, ElAkabawy GF and Faried MA. Protective role of broccoli extract on estradiol valerate-induced polycystic ovary syndrome in female rats. Eur. J. Anat. 2019; 23:121-129.

28. Khashana MH and Al-Turfib ZSM. Effect of alcoholic extract of brassica oleracea I. Var. Capitata plant leaves on glucose level and antioxidant activity in alloxan induced diabetic rats. Scientific Journal of Medical Research. 2017; 1:19-23.

29. Ouladsahebmadarek E and Khaki A. Ultra-structural Study by Transmission Electron Microscopy: Effect of Omega-3 on Ovary Cell Organelles after Experimental Induced Poly Cystic Ovary Syndrome. Int J Women's Health Reproduction Sci. 2014; 2:187-194.

30. Ugwah-Oguejiofor CJ, Bello SO, Okolo RU, Etuk EU, Ugwah O, Igbokwe VU and Umar M. Effect of aqueous extract of Ficusplatyphylla on female Wistar rats with estradiol valerate-induced polycystic ovarian syndrome. International Journal of Phytomedicine. 2014; 6:405-411.

31. Marcondes FK, Bianchi FJ and Tanno AP. Determination of the estrous cycle phases of rats: some helpful considerations. Braz J Biol. 2002; 62:609-14. | Article | PubMed

32. Kono Y. Generation of superoxide radical during autoxidation of hydroxylamine and an assay for superoxide dismutase. Arch Biochem Biophys. 1978; 186:189-95. I Article I PubMed

33. Mihara $M$ and Uchiyama M. Determination of malonaldehyde precursor in tissues by thiobarbituric acid test. Anal Biochem. 1978; 86:271-8. | 
Faried et al., Journal of Histology \& Histopathology 2019,

Article | PubMed

34. Amini L, Tehranian N, Movahedin M, Tehrani FR and Soltanghoraee H. Polycystic Ovary Morphology (PCOM) in Estradiol Valerate Treated Mouse Model. International Journal of Women's Health and Reproduction Sciences. 2016; 4:13-17.

35. Reddy PS, Begum N, Mutha S and Bakshi V. Beneficial effect of Curcumin in Letrozole induced polycystic ovary syndrome. Asian Pacific Journal of Reproduction. 2016; 5:116-122.

36. Jahan S, Munir F, Razak S, Mehboob A, Ain QU, Ullah H, Afsar T, Shaheen $G$ and Almajwal $A$. Ameliorative effects of rutin against metabolic, biochemical and hormonal disturbances in polycystic ovary syndrome in rats. J Ovarian Res. 2016; 9:86. | Article | PubMed Abstract | PubMed FullText

37. Von EckardsteinA. Androgens, cardiovascular risk factors and atherosclerosis. In: Nieschlag, E., and Behre, H.M. (Eds), Testosterone: action, deficiency, substitution. $2^{\text {nd }}$ ed. Springer, New York. 1998; 229258.

38. Croston GE, Milan LB, Marschke KB, Reichman M and Briggs MR. Androgen receptor-mediated antagonism of estrogen-dependent low density lipoprotein receptor transcription in cultured hepatocytes. Endocrinology. 1997; 138:3779-86. | Article | PubMed

39. Gardner CD, Fortmann SP and Krauss RM. Association of small lowdensity lipoprotein particles with the incidence of coronary artery disease in men and women. JAMA. 1996; 276:875-81. | Article | PubMed

40. Dahlgren E, Johansson S, Lindstedt G, Knutsson F, Oden A, Janson PO, Mattson LA, Crona $\mathrm{N}$ and Lundberg PA. Women with polycystic ovary syndrome wedge resected in 1956 to 1965: a long-term follow-up focusing on natural history and circulating hormones. Fertil Steril. 1992; 57:505-13. | Article | PubMed

41. Holte J, Gennarelli G, Berne C, Bergh T and Lithell H. Elevated ambulatory day-time blood pressure in women with polycystic ovary syndrome: a sign of a pre-hypertensive state? Hum Reprod. 1996; 11:238. | Article | PubMed

42. Wild RA, Rizzo M, Clifton S and Carmina E. Lipid levels in polycystic ovary syndrome: systematic review and meta-analysis. Fertil Steril. 2011; 95:1073-9 e1-11. | Article | PubMed

43. Sasikala $S$ and Shamila $S$. Unique rat model exhibiting biochemical fluctuations of letrozole induced polycystic ovary syndrome and subsequent treatment with allopathic and ayurvedic medicines. $J$ Cell Tissue Res. 2009; 9: 2013.

44. Sabuncu T, Vural H and Harma M. Oxidative stress in polycystic ovary syndrome and its contribution to the risk of cardiovascular disease. Clin Biochem. 2001; 34:407-13. | Article | PubMed

45. Liu J and Zhang D. [The role of oxidative stress in the pathogenesis of polycystic ovary syndrome]. Sichuan Da Xue Xue Bao Yi Xue Ban. 2012; 43:187-90. | PubMed

46. Rezvanfar MA, Ahmadi A, Saadi HA, Baeeri M and Abdollahi M. Mechanistic links between oxidative/nitrosative stress and tumor necrosis factor alpha in letrozole-induced murine polycystic ovary: biochemical and pathological evidences for beneficial effect of pioglitazone. Hum Exp Toxicol. 2012; 31:887-97. | Article | PubMed

47. Elahi MM, Kong $\mathrm{YX}$ and Matata BM. Oxidative stress as a mediator of cardiovascular disease. Oxid Med Cell Longev. 2009; 2:259-69. | Article | PubMed Abstract | PubMed FullText

48. Gurpinar T, Ekerbicer N, Uysal N, Barut T, Tarakci F and Tuglu MI. The effects of the melatonin treatment on the oxidative stress and apoptosis in diabetic eye and brain. ScientificWorldJournal. 2012; 2012:498489. | Article | PubMed Abstract | PubMed FullText

49. Kuyucu Y, Celik LS, Kendirlinan O, Tap O and Mete UO. Investigation of the uterine structural changes in the experimental model with polycystic ovary syndrome and effects of vitamin D treatment: An ultrastructural and immunohistochemical study. Reprod Biol. 2018; 18:53-59. | Article | PubMed

50. Tokunaga T, Morshed SR, Otsuki S, Takayama F, Satoh T, Hashimoto K, Yasui T, Ogawa S, Kanegae H, Yokote Y, Akahane K, Kashimata M, Satoh
$\mathrm{K}$ and Sakagami $\mathrm{H}$. Effect of antioxidants, oxidants, metals and saliva on cytotoxicity induction by sodium fluoride. Anticancer Res. 2003; 23:3719-26. | PubMed

51. Chen H, Adam A, Cheng Y, Tang S, Hartung J and Bao E. Localization and expression of heat shock protein $\mathbf{7 0}$ with rat myocardial cell damage induced by heat stress in vitro and in vivo. Mol Med Rep. 2015; 11:227684. | Article | PubMed

52. Khan AZ, Kumbhar S, Hamid M, Afzal S, Parveen F, Liu Y, Shu H, Mengistu BM and Huang K. Effects of Selenium-Enriched Probiotics on Heart Lesions by Influencing the mRNA Expressions of Selenoproteins and Heat Shock Proteins in Heat Stressed Broiler Chickens. Pak Vet J. 2016; 36:460-464.

53. Pournaderi PS, Yaghmaei P, Khodaei $H$, Noormohammadi $Z$ and Hejazi $\mathrm{SH}$. The effects of 6-Gingerol on reproductive improvement, liver functioning and Cyclooxygenase-2 gene expression in estradiol valerate - Induced polycystic ovary syndrome in Wistar rats. Biochem Biophys Res Commun. 2017; 484:461-466. | Article | PubMed

54. Vyas AK, Hoang V, Padmanabhan V, Gilbreath E and Mietelka KA. Prenatal programming: adverse cardiac programming by gestational testosterone excess. Sci Rep. 2016; 6:28335. | Article | PubMed Abstract | PubMed FullText

55. Hou M, Gu HC, Wang HH, Liu XM, Zhou CL, Yang Q, Jiang ZR, Lin J, Wu YM, Wu YT, Sheng JZ and Huang HF. Prenatal exposure to testosterone induces cardiac hypertrophy in adult female rats through enhanced Pkcdelta expression in cardiac myocytes. J Mol Cell Cardiol. 2019; 128:110. | Article | PubMed

56. Marsh JD, Lehmann MH, Ritchie RH, Gwathmey JK, Green GE and Schiebinger RJ. Androgen receptors mediate hypertrophy in cardiac myocytes. Circulation. 1998; 98:256-61. | Article | PubMed

57. Basualto-Alarcon C, Jorquera G, Altamirano F, Jaimovich E and Estrada M. Testosterone signals through mTOR and androgen receptor to induce muscle hypertrophy. Med Sci Sports Exerc. 2013; 45:1712-20. | Article | PubMed

58. A P, Varghese MV, S A, P SR, Mathew AK, Nair A, Nair RH and K GR. Polyphenol rich ethanolic extract from Boerhavia diffusa L. mitigates angiotensin II induced cardiac hypertrophy and fibrosis in rats. Biomed Pharmacother. 2017; 87:427-436. | Article | PubMed

59. Krenning G, Zeisberg EM and Kalluri R. The origin of fibroblasts and mechanism of cardiac fibrosis. J Cell Physiol. 2010; 225:631-7. | Article | PubMed Abstract | PubMed FullText

60. Corbould A, Kim YB, Youngren JF, Pender C, Kahn BB, Lee A and Dunaif A. Insulin resistance in the skeletal muscle of women with PCOS involves intrinsic and acquired defects in insulin signaling. Am J Physiol Endocrinol Metab. 2005; 288:E1047-54. | Article | PubMed

61. Montessuit $C$ and Thorburn A. Transcriptional activation of the glucose transporter GLUT1 in ventricular cardiac myocytes by hypertrophic agonists. J Biol Chem. 1999; 274:9006-12. | Article | PubMed

62. Allard MF. Energy substrate metabolism in cardiac hypertrophy. Curr Hypertens Rep. 2004; 6:430-5. | Article | PubMed

63. Stanley WC, Recchia FA and Lopaschuk GD. Myocardial substrate metabolism in the normal and failing heart. Physiol Rev. 2005; 85:1093129. | Article | PubMed

64. Kolwicz SC, Jr. and Tian R. Glucose metabolism and cardiac hypertrophy. Cardiovasc Res. 2011; 90:194-201. | Article | PubMed Abstract | PubMed FullText

65. Stenbit AE, Katz EB, Chatham JC, Geenen DL, Factor SM, Weiss RG, Tsao TS, Malhotra A, Chacko VP, Ocampo C, Jelicks LA and Charron MJ. Preservation of glucose metabolism in hypertrophic GLUT4-null hearts. Am J Physiol Heart Circ Physiol. 2000; 279:H313-8. | Article | PubMed

66. Liao R, Jain M, Cui L, D’Agostino J, Aiello F, Luptak I, Ngoy S, Mortensen RM and Tian R. Cardiac-specific overexpression of GLUT1 prevents the development of heart failure attributable to pressure overload in mice. Circulation. 2002; 106:2125-31. | Article | PubMed

67. Katz A.M. Heart Failure: Pathophysiology, Molecular Biology and Clinical Management. Philadelphia, Pa: Lippincott Williams \& Wilkins. 2000.

68. McLendon PM and Robbins J. Desmin-related cardiomyopathy: an 
Faried et al., Journal of Histology \& Histopathology 2019,

http://www.hoajonline.com/journals/pdf/2055-091X-6-8.pdf

doi: 10.7243/2055-091X-6-8

unfolding story. Am J Physiol Heart Circ Physiol. 2011; 301:H1220-8. | Article | PubMed Abstract | PubMed FullText

69. Sheng JJ, Feng HZ, Pinto JR, Wei $\mathrm{H}$ and Jin JP. Increases of desmin and alpha-actinin in mouse cardiac myofibrils as a response to diastolic dysfunction. J Mol Cell Cardiol. 2016; 99:218-229. | Article | PubMed Abstract | PubMed FullText

70. Pawlak A, Gil RJ, Walczak E and Seweryniak P. Desmin expression in human cardiomyocytes and selected clinical and echocardiographic parameters in patients with chronic heart failure. Kardiol Pol. 2009; 67:955-61. | PubMed

71. Milner DJ, Taffet GE, Wang X, Pham T, Tamura T, Hartley C, Gerdes AM and Capetanaki $Y$. The absence of desmin leads to cardiomyocyte hypertrophy and cardiac dilation with compromised systolic function. $J$ Mol Cell Cardiol. 1999; 31:2063-76. | Article | PubMed

72. Wang X, Osinska H, Dorn GW, 2nd, Nieman M, Lorenz JN, Gerdes AM, Witt S, Kimball T, Gulick J and Robbins J. Mouse model of desmin-related cardiomyopathy. Circulation. 2001; 103:2402-7. | Article | PubMed

73. Anesti $V$ and Scorrano L. The relationship between mitochondrial shape and function and the cytoskeleton. Biochim Biophys Acta. 2006; 1757:692-9. | Article | PubMed

74. Czarnowska E, Pawlak A, Brudek M, Zió"kowska L, Pronicki M and Kawalec W. Desmin cytoskeleton remodeling in dilated cardiomyopathy. Ann DiagPaediatrPathol. 2009; 13:73-77.

75. Pawlak A, Gil RJ, Kasprzak J, Walczak E and Slysz A. Cardiomyocyte desmin abnormalities - an accurate predictor of long-term survival in patients with chronic heart failure. Kardiol Pol. 2009; 67:724-33. | PubMed

76. Pawlak A, Gil RJ, Kulawik T, Pronicki M, Karkucinska-Wieckowska A, Szymanska-Debinska T, Gil K, Lagwinski N and Czarnowska E. Type of desmin expression in cardiomyocytes - a good marker of heart failure development in idiopathic dilated cardiomyopathy. J Intern Med. 2012; 272:287-97. | Article | PubMed

77. Pawlak A, Gil RJ, Grajkowska W, Nasierowska-Guttmejer AM, Rzezak J and Kulawik T. Significance of low desmin expression in cardiomyocytes in patients with idiopathic dilated cardiomyopathy. Am J Cardiol. 2013; 111:393-9. | Article | PubMed

78. Thornell L, Carlsson L, Li Z, Mericskay M and Paulin D. Null mutation in the desmin gene gives rise to a cardiomyopathy. J Mol Cell Cardiol. 1997; 29:2107-24. | Article | PubMed

79. Capetanaki Y, Milner DJ and Weitzer G. Desmin in muscle formation and maintenance: knockouts and consequences. Cell Struct Funct. 1997; 22:103-16. | Article | PubMed

80. Milner DJ, Mavroidis M, Weisleder N and Capetanaki Y. Desmin cytoskeleton linked to muscle mitochondrial distribution and respiratory function. J Cell Biol. 2000; 150:1283-98. | Article | PubMed Abstract | PubMed FullText

81. Xu L, Nagata $\mathrm{N}$ and Ota T. Glucoraphanin: a broccoli sprout extract that ameliorates obesity-induced inflammation and insulin resistance. Adipocyte. 2018; 7:218-225. | Article | PubMed Abstract | PubMed FullText

82. Shawky NM, Shehatou GSG, Suddek GM and Gameil NM. Comparison of the effects of sulforaphane and pioglitazone on insulin resistance and associated dyslipidemia, hepatosteatosis, and endothelial dysfunction in fructose-fed rats. Environ Toxicol Pharmacol. 2019; 66:43-54. | Article I PubMed

83. Mukherjee S, Gangopadhyay H and Das DK. Broccoli: a unique vegetable that protects mammalian hearts through the redox cycling of the thioredoxin superfamily. J Agric Food Chem. 2008; 56:609-17. | Article I PubMed

84. Wu L, Noyan Ashraf MH, Facci M, Wang R, Paterson PG, Ferrie A and Juurlink BH. Dietary approach to attenuate oxidative stress, hypertension, and inflammation in the cardiovascular system. Proc Natl Acad Sci U S A. 2004; 101:7094-9. | Article | PubMed Abstract | PubMed FullText

85. Thimmulappa RK, Mai KH, Srisuma S, Kensler TW, Yamamoto M and Biswal S. Identification of Nrf2-regulated genes induced by the chemopreventive agent sulforaphane by oligonucleotide microarray. Cancer Res. 2002; 62:5196-203. | Article | PubMed

86. Zhang DD. Mechanistic studies of the Nrf2-Keap1 signaling pathway. Drug Metab Rev. 2006; 38:769-89. | Article | PubMed

87. Jahan S, Abid A, Khalid S, Afsar T, Qurat UI A, Shaheen G, Almajwal A and Razak $S$. Therapeutic potentials of Quercetin in management of polycystic ovarian syndrome using Letrozole induced rat model: a histological and a biochemical study. J Ovarian Res. 2018; 11:26. | Article | PubMed Abstract | PubMed FullText

\section{Citation:}

El-Mehi AES and Faried MA. Ameliorating effect of Brassica oleracea (broccoli) extract on the myocardial damage induced by polycystic ovary syndrome in the adult female albino rat. J Histol Histopathol. 2019; 6:8. http://dx.doi.org/10.7243/2055-091X-6-8 